\title{
6. Die Sprache
}

Die Bewohner des Rauhen Kilikien sprachen ursprünglich und mit Sicherheit noch in hellenistischer Zeit neben dem Griechischen das Luwische, eine Schwestersprache des Hethitischen. ${ }^{1}$ Zumindest bei den inschriftlich bezeugten Personennamen läßt sich eine Kontinuität des Luwischen bis in die Kaiserzeit nachweisen. ${ }^{2}$ Zwar ist kaum davon auszugehen, daß in den Bergdörfern eine tiefgehende Hellenisierung erfolgte; Griechisch wurde zunächst nur in den Städten und Küstenregionen gesprochen. Doch es fand schließlich auch Zugang in die abgelegenen Regionen. So wurden die Verhandlungen zwischen P. Servilius Vatia, dem ersten römischen Eroberer Isauriens, und den isaurischen Abgesandten mit Sicherheit auf Griechisch geführt. ${ }^{3}$

Dennoch hielt sich die Ursprache lange: Die hagiographischen Quellen bieten vereinzelt Stellen, die auf eine Kontinuität bis in die Spätantike hindeuten. So gibt es noch im 6. Jahrhundert die Nachricht über einen Isaurier, der durch die Wunderkraft des Heiligen vermittelst eines ebenfalls geheilten Blinden von seiner Lähmung geheilt wurde. Alle Zeugen dieses Wunders hätten „,in ihrer eigenen Sprache“ ihre Begeisterung bekundet. ${ }^{4}$ In einer Fassung der an der Wende vom 4. zum 5. Jahrhundert entstandenen, jedoch in die Zeit der Apostel gesetzte Vita Cononis spricht der Heilige seine Landsleute in ihrer eigenen isaurischen Sprache an, um sie zum Christentum zu bekehren. ${ }^{5}$ Aufgrund des generell dubiosen Charakters von hagiographischen Quellen und der beiden Übersetzungsmöglichkeiten von $\delta$ ió $\lambda \varepsilon \kappa \tau o \varsigma$ läßt es sich zwar nicht völlig zweifelsfrei entscheiden, ob hier eine eigene isaurische Sprache oder nur das isaurisch eingefärbte Griechisch gemeint ist. ${ }^{6}$

Eine Deutung der Stellen im ersten Sinn ist aber aufgrund philologischer Argumente, wonach seit der klassischen Zeit mit $\gamma \lambda \hat{\omega} \tau \tau \alpha$ eher ein physischer Unterschied im lautlichen Ausdruck bezeichnet wird, wogegen $\delta$ ió $\lambda \varepsilon \kappa \tau o \varsigma$ eine anderssprachliche

1 Holl (1908) passim; THOMPSON (1946) 28; Jones (1964) II 994. III 332, Anm. 20; HouWINK TEN CATE (1965), 190-201; RoUGÉ (1966) 282; Mitford (1980) 1255: „That this population, outside the cities, was in general bilingual is certain". Emmanuel LAROCHE, s.v. 'Luwier, Luwisch, Lu(w)iya', Reallexikon der Assyriologie 7 (1987-1990), 181-184; Frank Starke, s.v. 'Luwisch', DNP 7 (1999), 528-533; RoBERT (1963) 322; TIB 5,1 99; NEUMANN (1980) 179.

2 Aufgelistet in Ramsay (1904) 291; Robert (1960), 348, Anm. 7 u. (1963) passim.

3 Zur Militärkampagne des P. Servilius Vatia s.u. Kap. III.1.3.

$4 \quad$ V. Simeonis Stylitiae Iunioris 188. 189, Z. 14: $\tau \hat{\text { in } i ́ t a ̣ ~ \delta i \alpha \lambda \varepsilon ́ \kappa \tau \omega . ~ V g l . ~ H o l l ~(1908) ~ 243 ; ~}$ ElTON (2000a) 294. Der jüngere Symeon Stylites lebte von 521-592, vgl. KW 291, 108.

$5 \quad V$. Cononis (Trautmann / Klostermann) p. 301, Z. 28f., p. 317, Z. $21 \mathrm{f}$.: Vom Heiligen

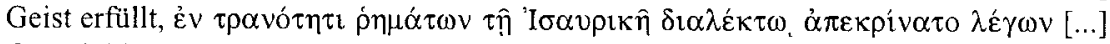

6 Gemeinhin kann $\delta$ tó $\lambda \varepsilon \kappa \tau o \zeta$ sowohl mit „Mundart, Dialekt, Ausdrucksweise“ einer Gegend als auch mit „Sprache“ übersetzt werden, vgl. LIDDELL-SCOTT 401 s.v. (,speech, language, way of speaking“"); BAUER, Griechisch-deutsches Wörterbuch zum NT 372 s.v. 
Äußerung beschreibt, ${ }^{7}$ und vor allem der expliziten Erwähnung dieses Wortes in den hagiographischen Quellen wahrscheinlicher: denn diese verfolgen die Absicht, Sprachwunder darzustellen, was bei einem bloßen Dialekt wenig glaubwürdig wäre. Umstritten ist in diesem Zusammenhang die Interpretation einer Stelle in der Apostelgeschichte bezüglich des luwischen Ur-Idioms. Hier heißt es, die Volksmenge in Lystra habe Lykaonisch gesprochen, ,lykaonisiert“. Gegen die Meinung, dies bedeute lediglich „,sie sprachen im griechischen Dialekt der Gegend“, da die Szene sich in einer vollständig gräzisierten Stadt abgespielt habe, könnte jedoch ein anderes Beispiel aus der Apostelgeschichte sprechen: Beim Schiffbruch in Malta heißt es von den Einheimischen, daß sie in ihrer eigenen Sprache sprachen. ${ }^{8}$ Auch andere kleinasiatische Ursprachen haben sich lange gehalten: so hat der heidnische Philosoph Apollonius von Tyana in der Severerzeit laut Philostrat ein Werk auf kappadokisch verfaßt. ${ }^{9}$ In einer Passage der von Georg von Alexandria verfaßten Vita des Johannes Chrysostomus ist die Eigensprache eines frisch christianisierten Taurus-Volks in der Armenia Tertia genannt; das Evangelium sollte in ihre Sprache übersetzt werden. Auch wenn die Stelle höchstwahrscheinlich fiktiv ist, so zeigt sie doch, daß der Autor zumindest die Existenz einer Ursprache in den abgelegenen Taurusregionen für möglich hielt. ${ }^{10}$ Somit ist von einem vereinzelten Überleben der isaurischen Eigensprache bis in die Spätantike auszugehen.

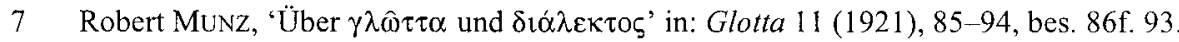

8 So Neumann (1980) $179 \mathrm{zu} \mathrm{Apg.} \mathrm{14,} \mathrm{11:} \mathrm{\lambda v \kappa \alpha oví \sigma \tau ıv.} \mathrm{Barbaren} \mathrm{in} \mathrm{Malta:} \mathrm{Apg.} \mathrm{28,} 2$. Frank STARKE, s.v. 'Luwisch', DNP 7 (1999), 528-533. 529 hält die Stelle für auf das Luwische verweisend; zudem sind alle ersten Personennamen der von Einheimischen stammenden griechischen Inschriften Kilikiens, Lykaoniens und Isauriens vom 1. bis ins 5. und 6. Jahrhundert luwisch: ROBERT (1963) 427-431; anders BuRgEss (1990).

9 Philostrat, V. Apollonii III 41. IV 19, gr.-dt. Vroni Mumprecht, München 1983; vgl. SARTRE (1991) 266.

10 Georg. Alexand., V. Ioannis Chrysostomi 59, in: Douze récits sur Saint Jean Chrysostome. Ed. François HaLkin, Subsidia Hagiographica 60, Bruxelles 1977, 237 ff. TrombLEY II (1994) 127 mit Anm. 261. 128 hält die Stelle gegen HALKIN für echt. 